\title{
Atuação Interdisciplinar no Preparo do Paciente para a Cirurgia Oncológica
}

\author{
Rangel, Priscila de Souza; Santos, Daniela Vivas dos; Baia, Wania Regina Mollo; \\ Andrade, Paulo Antonio da Silva; Silva, Rafael Thimótheo da \\ Instituto do Câncer do Estado de São Paulo - Icesp — priscila.souza@icesp.org.br
}

Introdução: o Ministério da Saúde, em 2000, regulamentou o Programa Nacional de Humanização, que teve como objetivo 0 aprimoramento das relações entre hospital/comunidade, visando melhorar a qualidade e a eficácia dos serviços de saúde e promover uma cultura humanizada de atendimento. em relação ao tratamento oncológico a humanização é parte integrante do cuidado, pois o diagnóstico traz consigo, incertezas, medos, angústia e sofrimento, sendo a cirurgia ainda a principal opção terapêutica com finalidade curativa em pacientes portadores de tumores sólidos e em alguns tratamentos paliativos, podendo decorrer em mutilações com alto impacto na qualidade de vida do paciente. Assim, o paciente precisa estar bem preparado para o tratamento, evitando a suspensão da cirurgia por comorbidades descompensadas (desnutrição, HAS ou DM) ou ainda ausência de recursos sociais para continuar com as etapas do tratamento em âmbito domiciliar. Visando atender e preparar o paciente com indicação cirúrgica adotamos em nosso serviço o modelo de atendimento psicoeducativo em grupo. Objetivos: Acolher o paciente; oferecer informações específicas sobre a cirurgia indicada; identificar riscos biopsicossociais que possam comprometer a adesão e o tratamento. Se necessário é realizado atendimento individual específico. Materiais e Métodos: o atendimento é organizado em grupos de pacientes com procedimentos cirúrgicos semelhantes: Mastologia, gastroenterologia, urologia; cabeça e pescoço e ginecologia. a atividade contempla informações referentes aos cuidados pré e pós-cirurgia, apresentação de vídeo contendo informações básicas do período pré e trans-operatório. É aplicado questionário de avaliação de risco nutricional e social (ausência de cuidador e/ou rede de apoio para reabilitação no domicilio), enfermagem (duvidas, uso de marcapasso, anticoagulantes, diálise e cuidados no domicilio). a equipe é composta por enfermeiro, psicólogo, fisioterapeuta, fonoaudiólogo, nutricionista e assistente social e tal composição pode variar de acordo com as características de cada grupo, sendo obrigatória a presença do enfermeiro e psicólogo. ao término do grupo é analisado o instrumento aplicado ao paciente e avalia-se a indicação de abordagem individual, caso não haja, o paciente é considerado apto para a cirurgia. Se identificado alguma necessidade específica o paciente é avaliado individualmente. Resultados: em 2013 a adesão aos grupos foi de 86\%; adesão a cirurgia: 98\% (enquanto a adesão dos pacientes que não participaram do projeto foi de $89 \%$ ) Intervenções individuais $8 \%$ do total. Considerações finais: Os resultados do projeto mostram que o grupo psicoeducativo pré-cirúrgico foi um fator contributivo para a adesão a cirurgia, favorece o acolhimento e identificação precoce dos pacientes de risco.

Rangel, Priscila de Souza; Santos, Daniela Vivas dos; Baia, Wania Regina Mollo; Andrade, Paulo Antonio da Silva; Silva, Rafael Thimótheo da. Atuação Interdisciplinar no Preparo do Paciente para a Cirurgia Oncológica. In: Anais do Congresso Internacional de Humanidades \& Humanização em Saúde [= Blucher Medical Proceedings, num.2, vol.1]. São Paulo: Editora Blucher, 2014. ISSN 2357-7282 DOI 10.5151/medpro-cihhs-10789 